\title{
Nested risks and responsibilities: Perspectives on fertilizer from human urine in two U.S. regions
}

\author{
Tatiana Schreiber ${ }^{a *}$ \\ Rich Earth Institute and Keene State College \\ Shaina Opperman b and Rebecca Hardin c \\ University of Michigan \\ Julia Cavicchid \\ Rich Earth Institute
}

\author{
Audrey Pallmeyer ${ }^{\mathrm{e}}$ \\ University of Michigan
}

Kim Nace ${ }^{f}$

Rich Earth Institute

Nancy Love ${ }^{g}$

University of Michigan

Submitted August 21, 2020 / Revised December 22, 2020, and February 12, 2021 / Accepted February 13, 2021 / Published online June 15, 2021

Citation: Schreiber, T., Opperman, S., Hardin, R., Cavicchi, J., Pallmeyer, A., Nace, K., \& Love, N. (2021). Nested risks and responsibilities: Perspectives on fertilizer from human urine in two U.S. regions. Journal of Agriculture, Food Systems, and Community Development, 10(3), 221-242. https://doi.org/10.5304/jafscd.2021.103.016

Copyright (C 2021 by the Authors. Published by the Lyson Center for Civic Agriculture and Food Systems. Open access under CC-BY license.

\section{Abstract}

This paper reports on social research investigating perceptions concerning the diversion of urine from the waste stream and its use as fertilizer in two

a * Corresponding author: Tatiana Schreiber, Rich Earth Institute; 355 Old Ferry Road; Brattleboro, VT 05301 USA; and Department of Environmental Studies, Keene State College; +1-802-387-2781; tatiana@,richearthinstitute.org

b Shaina Opperman, School for Environment and Sustainability, University of Michigan; Samuel T. Dana Building; Ann Arbor, MI 48109 USA; +1-248-756-3431; oppersha@umich.edu

c Rebecca Hardin, School for Environment and Sustainability, University of Michigan; Samuel T. Dana Building; Ann Arbor, MI 48109 USA; +1-774-645-9519; rdhardin@,umich.edu

d Julia Cavicchi, Rich Earth Institute; 355 Old Ferry Road; Brattleboro, VT 05301 USA; +1-240-888-0209; julia@,richearthinstitute.org

e Audrey Pallmeyer, Community Health Services, University of Michigan; 2025 Traverwood Drive, Suite A2; Ann Arbor, MI 48105 USA; +1-612-978-5780; audnp@umich.edu

f Kim Nace, Rich Earth Institute; kim@,richearthinstitute.org. Kim Nace is now with Rich Earth LLC. study regions, New England and the Upper Midwest. We hypothesized that discomfort or disgust might affect acceptance of such a shift in human "waste" management. However, our findings suggest that a more significant concern of those po-

g Nancy Love, University of Michigan, Department of Civil and Environmental Engineering, 183 EWRE Building, 1351 Beal Avenue, Ann Arbor, MI 48109; 734-763-9664; nlove@umich.edu

\section{Funding Disclosure}

This research was carried out as part of a larger project, including technical teams, funded by the Innovations at the Nexus of Food, Water, Energy and Water Systems (INFEWS) section of the National Science Foundation (NSF), grant 1639244, "Advancing Technologies and Improving Communication of Urine-Derived Fertilizers for Food Production within a Risk-Based Framework."

\section{Author Note}

During the research, writing, and revision of this article, Kim Nace was co-founder and a co-director of Rich Earth Institute. She has since left the research division of the organization to found and serve as CEO of Rich Earth LLC, a forprofit division that develops products and tools for urine nutrient recovery. 
tentially involved in this process may be distrust of how economic interests influence scientific and technical information. Both physical risks (to the environment and public health) and socio-political risks (to fragile farm economies and consumer communities) play out at individual, household, regional, and global scales. We describe the intersection of these complex understandings as nested risks and responsibilities that must inform the future of urine reclamation. Our respondents' shared concern about environmental risks has already galvanized communities to take responsibility for implementing closed-loop alternatives to current agricultural inputs and waste management practices in their communities. Attention to these nested understandings of both risk and responsibility should shape research priorities and foster participatory approaches to urine nutrient reclamation, including strategies for education, planning, regulation, technology design, and agricultural application.

\section{Keywords}

Community Development, Human Urine, Fertilizer, Participatory Action Research, Wastewater Management, Food Systems, Circular Economy, Risk Perception

\section{Introduction}

This paper reports on social research investigating attitudes about the diversion of urine from the waste stream and its use as fertilizer in two study regions, New England and the Upper Midwest. We initially hypothesized that individuals might experience visceral negative reactions to resource recovery from human urine, as has been the case with the land application of biosolids and the potable reuse of highly purified wastewater (Jones, 2011; MacPherson, 2015; Mason-Renton \& Luginaah, 2018). Our findings suggest, however, that it is distrust in how economic interests influence scientific and technical information, not disgust about biological processes, that might affect widespread uptake of urine recycling (Stern \& Baird, 2015). We also find that concern about both environmental risks and the resilience of local economies is galvanizing efforts at local stewardship and sustainable practices that could enhance the spread of closedloop alternatives to current waste management and agricultural inputs. However, as Lachapelle (2008) has emphasized, to build a "sense of ownership" on the part of all participants in projects involving multiple layers of socio-technical change, "a focus on trust in community development research and practice would draw attention to how various voices view risk" (p. 56). This paper describes the complex understandings of our respondents as the nested risks and responsibilities that can shape the future of urine reclamation. Our framework builds upon the nested risk system model elaborated by Blair, Lovecraft, and Kofinas (2014), emphasizing that local values and perceptions must be integrated into adaptive risk management. Our effort here is to elaborate those perceptions, not to "manage risk" per se (Beck, 1992), but rather to foster knowledge exchange leading to research partnerships and inclusive strategies for recycling bodily nutrients. We analyze participants' understandings of both physical risks (to the environment and public health) and socio-political risks (to fragile farm economies and consumer communities), as well as concepts of individual and collective responsibility for addressing these risks. We then consider how they play out at individual or household, community, regional, and international scales.

The research was conducted by a joint social science team including faculty, postdoctoral, and graduate students from the University of Michigan in Ann Arbor and the Rich Earth Institute in Brattleboro, Vermont. It was part of a larger project, including technical teams, funded by the INFEWS section of the National Science Foundation. Conducting our study in the New England and the Upper Midwest regions enabled us to consider how both geographic location and scale of implementation will influence patterns of adoption. Several recent studies have addressed the value of urine reclamation to achieve sustainability goals, including completing nutrient cycles and reducing greenhouse gas emissions (see Hilton et al., 2021; Legrand et al., 2020; Simha \& Ganesapillai, 2017). Other site-specific social studies conducted across the globe on urine diversion have emphasized different facets of the complex risks and understandings caught up in both the technological implementation and agricultural reuse of human urine. These 
have included research with diverse communities such as general public perspectives in South Africa (Wilde et al., 2019); farmers, college students, and consumers in Switzerland (Lienert et al., 2003; Lienert et al., 2006; Pahl-Wostl et al, 2003); and pilot implementations in university settings and villages in Australia (Abeysuriya et al., 2013; Cook et al., 2013). These studies have been focused on behavioral and attitudinal approaches of specific stakeholder groups. In comparison, North American social research into this topic has been relatively limited. Building on Ormerod's (2016) work proposing that knowledge gaps in sustainable sanitation must be addressed, our study sought to deepen our understanding of the values, beliefs, and concerns of diverse participants in two regions, thus facilitating equitable knowledge exchange.

The wider project of which our work is part explores how human urine has the potential to complete the nutrient cycle (preventing nutrient pollution and supporting sustainable agriculture) while also reducing greenhouse gas emissions (Hilton et al., 2021). ${ }^{1}$ From the wastewater perspective, urine contributes approximately $75 \%$ of the nitrogen and $50 \%$ of the phosphorus in domestic wastewater (Vinnerås, 2006), nutrients which are rarely removed before their discharge into waterways, resulting in nutrient pollution that contributes to harmful algal blooms. On the agricultural side, it is estimated that urine could replace 9 billion pounds of greenhouse gas-emitting synthetic fertilizer each year in the US and maintain yields while limiting pollution, as urine contains vital plant nutrients, including nitrogen, phosphorus, and potassium. Small-scale field and lab trials by our technical teams are beginning to generate relevant data in these directions (A. Noe-Hays, personal communication, 2020).

Ecological sanitation, including urine diversion, potentially can enable climate-resilient community development by offering a safe, affordable path for waste collection and reuse (Cavicchi et al., 2020; Les Greniers de l'Abondance, 2020). On the consumer side, a large-scale survey explored attitudes regarding urine-derived fertilizers (UDFs) to determine the potential for these to be embraced as an alternative at scale (Segrè Cohen et al, 2020). But such potential cannot be realized without also attending to the hopes, fears and concerns of individuals and communities; that is the focus of the present qualitative study. Our work takes seriously how participants' aspirations to responsible action for environmental sustainability relate to notions of nested risk.

Our results indicate that when participants learned about the nutrient value of human urine, though they often ascribed potential disgust or discomfort to others, they themselves were often open to considering its use as a fertilizer. Humor was frequent and helpful in enabling discussions about the possible benefits of urine recycling, while bolistic thinking about environmental risks and responsibilities (on both individual and community levels) appeared to be an overarching motivation for interest in the topic. ${ }^{2}$ However, many respondents expressed uncertainties about the safety of urine recycling that they embedded in their larger concerns regarding widespread water and food contamination in local communities.

Respondents also expressed variations on the theme of taking responsibility for human waste in the current context of ecological and economic risk (Alaimo, 2016). However, many also expressed anxiety about which institutions and individuals are trustworthy in this regard. In particular, some respondents noted distrust in agroindustry and of wastewater and drinking water management systems. Several of these individuals, and others, spoke of needed work toward the protection of watersheds and food supply chains. In sum, our team's work illuminates fears of infection or contamination risk (particularly important during a global pandemic) and concerns about ownership, decision-making structures (Stern \& Baird, 2015), and equitable generation and distribution of profit from urine, given that it is a substance produced by

\footnotetext{
${ }^{1}$ See also https://news.umich.edu/peecycling-payoff-urine-diversion-shows-multiple-environmental-benefits-when-used-at-city-scale/

2 We use the term "holism" to reference expressions by our respondents that individuals, society, and the environment are intertwined and interdependent. This coding category thus emerged for us as appropriate in ways we describe in a separate methods manuscript (Schreiber et al., 2020).
} 
human bodies.

These findings have important implications for questions of food sovereignty (Carney, 2012), nutrient sovereignty (Tornaghi, 2017), and watershed stewardship. As our participants suggest, completing the nutrient cycle — and therefore addressing both food and wastewater system challenges - can only be done successfully through transparent and accurate communication of research results that directly address their concerns. Guiding system change with this kind of ongoing dialogue is vital when there are knowledge conflicts (Heiss \& Suozzo, 2020). Participants indicated that this approach could support the adoption of alternatives to mainstream practices, as has been demonstrated in existing alternative, community-based watershed stewardship models. In New England, for example, a group of farmers have self-organized to manage riparian flooding by altering their cultivation practices and working on watershed conservation issues up and down the Connecticut River (Vermont Farmer and Environmental Advocate, 2018). In Michigan, similar experiments are underway, amidst growth in river-based conservancies and their collaborations with both recreational and agricultural organizations (Aparicio, 2019). These responses affirm the need to design urine reclamation systems through a dialogical approach that prioritizes local knowledge.

\section{Applied Research Methods}

The U.S. Department of Agriculture (U.S. Department of Agriculture, National Agricultural Statistics Service [USDA NASS], 2017) agricultural census suggests some similar trends in the two regions we included in this project. For example, there have been recent losses in farm numbers, increases in farm size, and substantial increases in organic production. Both areas evidence the low awareness of urine diversion and reuse suggested by recent research (Ishii \& Boyer, 2016). Given our initial concerns that this practice could become stigmatized, we wanted to ensure that all participants engaged by each of our research methods-surveys, interviews and focus groups-had access to a common base of educational information from which might emerge participants' most important categories of conversation. Thus, each survey instrument and interview or focus group guide included a brief description of urine's nutrient content (i.e., fertilizer value) as well as results from Rich Earth's yield studies applying sanitized urine to hay in Brattleboro. ${ }^{3}$ The information also mentioned water conservation and wastewater treatment efficiency benefits that could be derived from urine diversion. The entire research team assessed all educational language for clarity, accuracy, and avoidance of bias, with final approval from the University of Michigan Institutional Review Board Human Subjects committee (No. HUM00116968).

In addition to the information provided in the focus group guides, participants in the Michigan focus group, one of the two New England general public focus groups, and both New England farmer focus groups watched a 6-minute animated video produced by New Water Resources ${ }^{4}$ that also described the concept of urine derived fertilizer.

Both interviews and focus groups utilized semi-structured guides with open-ended questions to facilitate rich dialogue. The guides were adapted to reflect interviewees' areas of knowledge. All interviewers and focus group facilitators used these guides but were free to ask additional questions emerging from the conversations.

\section{Context Methods: Surveys}

To discover categories of interest among various constituents and to shape our focus group and interview guides, we first implemented 400 Qualtrics surveys at festivals and farmers markets in Vermont and Michigan that assessed attitudes about the use of urine as a fertilizer across a range of demographics. As an example of how the surveys provided context, we asked participants to rank in importance potential implications of urine diversion and reuse. Discovering that mitigation of cli-

\footnotetext{
3 The Rich Earth Institute purifies and concentrates urine into a ready-to-use fertilizer product through a four-step process of acidification, pasteurization, freeze concentration, and charcoal filtration (see https://richearthinstitute.org/).

${ }^{4}$ New Water Resources is a group that has worked internationally on water reuse issues (https://www.newwaterresources.com). The animation mentioned and a shorter version can be seen at https://www.youtube.com/channel/UCSRKi2j0HQvVNRoC2DKV2eQ.
} 
mate change was ranked high determined the inclusion of a question about climate change on our interview and focus group guides. These data shaped and strengthened our research design, but the results reported here rely primarily on our core methods: the richer responses offered by the interviews and focus groups that followed the survey phase of our work.

\section{Core Methods: Interviews}

We conducted in-depth interviews lasting 60 to 90 minutes-13 in New England and 11 in the Upper Midwest - with individuals selected for their specific knowledge areas, parallel across both sites. These included environmental advocates, city planners, wastewater treatment engineers and plant operators, farmers, agricultural educators, agribusiness leaders, nutrient management advisors, and soil scientists. We also interviewed two legislators in $\mathrm{New}$ England and two lakeside property owners concerned about water quality in the Upper Midwest. Interviewees at both sites had no previous connection to Rich Earth Institute except for three farmers (identified in the ensuing narrative) who are currently partnering with the institute to apply sanitized urine. Participants were informed that their responses would be kept confidential. Although many of them felt comfortable with being identified, because others did not, we have chosen to deidentify respondents here.

\section{Core Methods: Focus Groups}

In New England we conducted four focus groups; two consisted of members of the general public and two of farmers. General public participants were all recruited by fliers describing a discussion on "the use of human waste as an agricultural resource." In our recruitment process we pursued participation only from households with incomes below US $\$ 30,000 /$ year both to broaden inclusivity beyond the parameters of current early adoption communities and to collaborate with stakeholders frequently excluded from discussions on technology and policy change. The two other focus groups in New England consisted of farmers recruited through agricultural listservs for the southern Ver- mont region, email invitations to farmers within 30 miles $(48 \mathrm{~km})$ of Brattleboro, and phone calls to follow up with these farmers. These groups ended up with a small number of participants, five overall, which may have been influenced by the late March timing converging with the busy spring season. All farmers worked at a small scale, common in Vermont's agricultural landscape, with farms ranging from under 6 acres (2.4 ha) up to 300 acres (121 ha). One farm was certified organic, one was "conventional," and the others identified as either "organic, not certified" or "beyond organic." While no large-scale commodity farmers participated, we urge their inclusion in future research.

In the Upper Midwest, we conducted only one pilot general public focus group consisting of four undergraduate students at the University of Michigan and one resident of the surrounding Ann Arbor area, recruited through fliers similar to those in Vermont. The research team decided instead to invest its limited resources in the Upper Midwest through interviews with key stakeholders as described above. Although the small number of focus groups included in this data is a limitation, transcripts of these rich conversations provided insights that informed our subsequent interviews and illuminated a host of areas for the ongoing research we recommend. See Appendix A for details on the focus groups and interviews.

\section{Data Analysis}

We transcribed the audio of interviews and focus groups in full. Then, two researchers who did not participate in conducting the interviews coded each transcript in Microsoft Word using a common coding guide. Seventeen codes (with subsections) were initially elaborated based on key themes that emerged in the interviews and focus groups, iteratively revised as our team discussion proceeded. Within some categories we developed scales from "low" to "middle" to "high" values. Our interdisciplinary team used a consensus process to arrive at the coding categories and subcategories. ${ }^{5} \mathrm{We}$ merged the coders' independent results into master documents for group analysis with interactive and collaborative methods described in a separate pa-

\footnotetext{
${ }^{5}$ The coding categories we identified are described in Appendix B.
} 
per (Schreiber et al., 2020; see also Saldaña, 2015). We extracted the coders' comments into a Microsoft Excel spreadsheet to observe how frequently a specific code was used and its co-occurrence with other codes. ${ }^{6}$ Given our use of multiple coders, the total occurrence suggests the strength of consensus in our analysis and relative frequency of results, not specific numbers of statements. We thus employ semi-quantified language that is empirically based in the spreadsheet results such as "most," "many," or "often" to designate concepts proportionately representative of data, and "some" or "few" to describe outlier examples not aligning with major trends.

\section{Results}

Each section below reports key results in order of respondent categories - first the general public, then farmers, then specialists - to help guide the reader through our findings. Subheadings below indicate categories which emerged most frequently in our coding analysis. The quotations we include from interviews and focus groups were selected to illustrate specific ways that respondents expressed the important themes that emerged from our data.

\section{Overarching Motivations}

As noted earlier, we coded as holism expressions on the part of our respondents that connect ecological system health and function with the economic health of local communities (for instance, efforts to reduce the use of external or energy intensive inputs). This concept emerged as an overarching motivation for those considering urine diversion and reuse, sometimes in tentative language, but with surprising frequency.

Among the general public, while holism may not have been an overt theme, the concept of closing loops resonated. Many expressed a desire for connections within their communities to address common problems. For example, one focus group participant said:

I've just been thinking about it, so, if the pee is . . locally acquired . . I f feel . . . if it's like a community effort almost, like we're all going

${ }^{6}$ We modified this method from Knoch (2018). to do this together and the money's gonna come back to our community and we're going to make the crops in our community less ... pollute them less. . . . I feel like it could be like a group effort. (General Public Focus Group 1, 2017)

A few participants also supported urine diversion because it could help farmers. One focus group participant noted:

Farmers have it pretty tough right now, they always have it pretty tough ... this would help because it would be one less thing they'd have to worry about ... assuming that it all checked out and they could get a good quantity of it. (General Public Focus Group 2, 2017)

However, several participants raised concerns that production and processing of urine to meet safety standards could undermine the circular economy promise. For example, one respondent said:

Urine derived fertilizer ... just seems like it would still be an energy intensive way to get your fertilizer. ... If you want to get the greenest possible formula, if straight urine is still safe. ... I think reused urine seems more, like, natural. (General Public Focus Group 1, 2017)

Farmers in our focus groups also expressed interest in waste-related innovation to complete the food-nutrient cycle. One said:

I've always been really interested in ... completing the cycle, from human waste back to food... using as little synthetic or engineered substances that maybe have a lot of energy input. ... We really try to reduce, so this seemed like a really interesting thing ... depending on how much processing the urine would need. (Farmer Focus Group 1, 2018)

Yet an important theme in farmers' responses was the economic calculation they would have to make about any innovations. Our codes differenti- 
ated between environmental, economic and other potential benefits and concerns around urine diversion and reuse. When we located co-occurrences among coded comments, we found that farmers often spoke about holism by evoking reuse, local scale actions, and recycling-ideas in line with notions of circular economies.

Respondents seemed in fact to enjoy thinking out loud about more and less localized, and smaller- and larger-scale visions of this idea. For example, one suggested:

If it could $\ldots$. become . . . an industry that sort of weaves itself into the community in some way, then that also seems ... incredible and positive. If you're collecting local urine from local people, then there's going to be some level of cross-accountability ... of shared responsibility for keeping it clean or that sort of thing, then it becomes an opportunity for offering employment for people who are running those programs. You know, there's all sorts of positive, positive impacts that could have; it could also go the other way where it becomes one large company that just trucks the urine out to some location and processes it and then trucks it back and no benefits are really realized because it becomes a product that is, you know, sort of dictated by the market I guess. (Farmer Focus Group 1, 2018)

Among specialists, the theme of holism was also central to their thinking about this topic, but in different ways than expressed by farmers. For example, an environmental advocate who heads a large water conservation group noted that the organization strives to consider ecosystems as a whole. Urine diversion might fit into that vision when it reduces the amount of nutrients (i.e., nitrogen and phosphorus) entering waterways:

Our concern is that we not just focus on particular numbers, but that we begin to express the definition of a healthy river in terms of its biology — not milligrams per liter, not cubic feet per second-but what communities and guilds and structures of diatoms, bugs, fish, live in that system? [This is] a much more so- phisticated expression ... [than more reductionist thinking] and nutrients are driving that conversation. ... So, we recognize, there's too many nutrients in our aquatic systems. There's too many nutrients in our atmospheric systems and often in soil systems, they're completely saturated with things like phosphorus, and we do not yet have the best use of nutrients. (Massachusetts Environmental Advocate, 2017)

However, the advocate noted that for the organization's constituents to consider urine diversion and reuse, they would need to know the specific possible climate benefits, reduction in pollution, or benefits to aquatic ecosystems that urine diversion might provide:

Does diverted urine in whatever form as an agricultural product, in fact, promote more responsible use and get it out of the wastewater stream? We would need to be able to say "Yeah, this has got a practical effect of X percentage of reduction.". . . You know, that type of work to be able to demonstrate it. (Massachusetts Environmental Advocate, 2017)

This advocate's recognition of the need to address his constituents' concerns is echoed in many of our respondents' pondering of how their communities can and should respond to both the potential benefits of urine recycling and the potential challenges to its implementation.

\section{Considerations of Community Responsibility}

Respondents indicated several specific potential benefits of urine recycling beyond their personal concerns. For example, they noted water conservation, energy efficiency, and the reduction of chemical inputs into agriculture (possibly lowering costs for agricultural production), suggesting that many of our respondents share a sense of community or collective responsibility to both address environmental harms and support local economies.

Among the general public in our focus groups, many saw urine diversion's potential to conserve water through reduced flushing as the biggest benefit that could drive them to adopt the technology. They thought water conservation would motivate 
people in other areas of the country facing water shortages and would personally consider changing their toilets to urine-diverting fixtures if reductions in water bills significantly covered the cost.

In considering food fertilized with UDF, the potential to reduce environmental impacts of current commercial fertilizers (mining for phosphorus, for example) and the carbon footprint associated with shipping these inputs worldwide were important factors to participants, especially if these environmental benefits helped farmers and/or translated into lower prices for consumers.

Farmers had a range of reasons for their interest in UDFs. For example, one commented that "there's very few sources [of high-nitrogen fertilizers] that are approved organically, and so the fertilizer we use that we purchase doesn't even have nitrogen in it" (Farmer Focus Group 2, 2018). This was a key reason for his interest in UDFs.

Farmers also hoped that a local source of fertilizer could reduce the transportation costs of bringing in fertilizers and/or have other benefits. For example, urine contains a range of micronutrients in addition to the macronutrients nitrogen $(\mathrm{N})$, phosphorus $(\mathrm{P})$, and potassium $(\mathrm{K})$, and secondary nutrients such as calcium and magnesium, an appealing attribute to one participant, who noted that "most soils have certain limiting micronutrients. And so, having a diverse product that you are applying, because the human diet is diverse. ... I would think that would also be a positive thing" (Farmer Focus Group 2, 2018).

Several farmers connected these personal concerns to wider community needs. For example, one said: "The idea that it's better for the land and my community would be the other huge impact, you know, because I want to do the best I can to take care of our land and our water ... those are the biggest things for me" (Farmer Focus Group 1, 2018). Farmers were aware that urine, like other fertilizers, would need to be applied with care so as not to create the same problem of nutrient pollution that other fertilizers do, but the possibility that it could be used more precisely was of interest to many of the farmers in this study.

Among specialists, there are a range of motivations that they felt create opportunities for adoption of urine diversion and reuse. For example, a legislator with many years of working on wastewater issues and regulation noted that removing nitrogen and phosphorus from the waste stream would be highly beneficial from an economic point of view:

The most expensive way to reduce phosphorus and nitrogen discharged into the waters of the state ... is, in fact, to require higher levels of treatment at the wastewater treatment facilities. ... We need to think in other directions, and that's where something like this comes in. ... It's pretty imaginative. . . It takes hands-on work to be able to get it right ... but if costs are lower, and I suspect they will be, then that is definitely a plus for this as a direction for us to go. (Vermont Legislator 1, 2017)

A New England nutrient management specialist said the idea of using human waste as a resource makes sense because of the region's population density:

I've just always ... had a consciousness that [given] our nutrient issues in New England ... we need to cycle our own waste. Because, there's a very disproportionate ... distribution of nutrients. ... So, we produce a lot, but we don't have a large demand for nutrients. ... We would need to be an exporter, basically. (Massachusetts Agricultural Educator, 2018)

Another agricultural educator explained that farmers already face climate-driven changes to the technological and seasonal aspects of their work, and mentioned that some farmers are looking for ways to address the effects of their emissions and that this could motivate interest in UDFs:

We have some farmers who are interested in mitigation and reducing their carbon footprint. ... We talk about finding organic nitrogen sources instead of synthetic nitrogen sources because of the high carbon footprint of . . fixing nitrogen in synthetic fertilizers, [so] any organic nitrogen source like this would have climate benefits. (Vermont Agricultural Educator, 2017) 
Respondents shared an apparent sense of both personal and collective responsibility for addressing larger environmental issues. However, they also noted a range of concerns that reveal the specific ways in which they feel vulnerable. Such perspectives ranged from their personal health or finances to the well-being of their communities, and from the integrity and resilience of the environment to the costs and challenges of navigating institutional change. Another significant theme that emerged was the question of who should have responsibility for addressing these many challenges and who can be trusted to do so with integrity. Below we explore some of these specific concerns. Their "nested" nature means that the obstacles and opportunities for UDF are linked.

\section{Vulnerability, Risk, and Trust}

The larger NSF-funded project, of which our team's social research is a part, has centered around mitigating risks to individual health (documenting and limiting the virological, pharmaceutical, or bacteriological contaminants that might be found in human urine, for example). Yet we found most respondents to be equally or more concerned about wider risks to the health and safety of their communities from environmental toxins and contaminants. For example, discussions about the potential risk of microconstituents in urine quickly led to discussion about likely contaminants in other fertilizers and "natural" soil amendments commonly used in agriculture. Many acknowledge that they share this vulnerability with other species such as aquatic life, plants, and animals in their watersheds and food supply chains. These wider risks, in aggregate, combined with a lack of trust about how science gets used and how communication happens in formal political and governmental channels, as well as informal networks, has created what we describe as a set of "nested risks" from the combined vulnerabilities.

These concerns are not synonymous with, say, conspiracy theories. Rather they reflect understandings of the limitations of scientific, commercial, and policy processes where knowledge is not complete. They also reflect experience with and insights about the individuals or organizations, and the scale and scope (e.g., personal, community, regional, national) at which risk mitigation might take place (see Figure 1).

In both focus groups and interviews, we asked respondents what information would help address their uncertainties and guide their decisions about using UDFs. Among the general public, answers to their questions about human and environmental safety measures were most frequently mentioned. Participants would want to know that it has been treated, how it has been treated, and what the safety standard used means for them. One participant explained:

Since it's used from humans, I worry about diseases or infections being transmitted. ... So I would want to know ... is it safe, and how is it safe before I would go ahead and be like yeah, I support this 100\%. (General Public Focus Group 1, 2017)

To further aid their decision-making, participants also wanted to better understand what implementing urine diversion would look like and see specific research findings on the costs and benefits of this potential change. They wanted to know what new infrastructure would be required and what it would cost; how urine would be collected; the form the fertilizer would take and how it would be applied; and how potential contaminants would interact with plants and the soil over time.

However, when asked who they felt should regulate or ensure the safety of UDFs, the conversation in our general public focus groups quickly became complicated. For example, one respondent said:

The way I'm thinking with this is ... is this really something to help the environment, or is it just a Band-Aid to get rid of solid waste? ... I'm looking to see who is benefiting from this, who stands to make money and who is going to lose.... Are we going to be on the losing end with crap, because it's going to be cheaper, and we can buy [it] ... and they're selling to us as "it's great" when down the road it's really killing us? (General Public Focus Group 2, 2017) 


\section{Figure 1. Nested Risks and Responsibilities Identified by Participants}

Graphic representation of the nested risks revealed by our research, in concentric circles that correspond to the scales at which risks exist and/or are experienced by respondents. The color coding represents different types of risk at each scale, as they connect to and drive or inform one another. These range from human and environmental health (red), to those concerning complex environmental and social systems (green), to those related to implementation and information needs (blue), and finally considerations of governance and regulatory factors (grey). Of course, by "scale" we mean to include the permeability of these boundaries and the new relationships created among people and across differing scales (see Sayre, 2009).

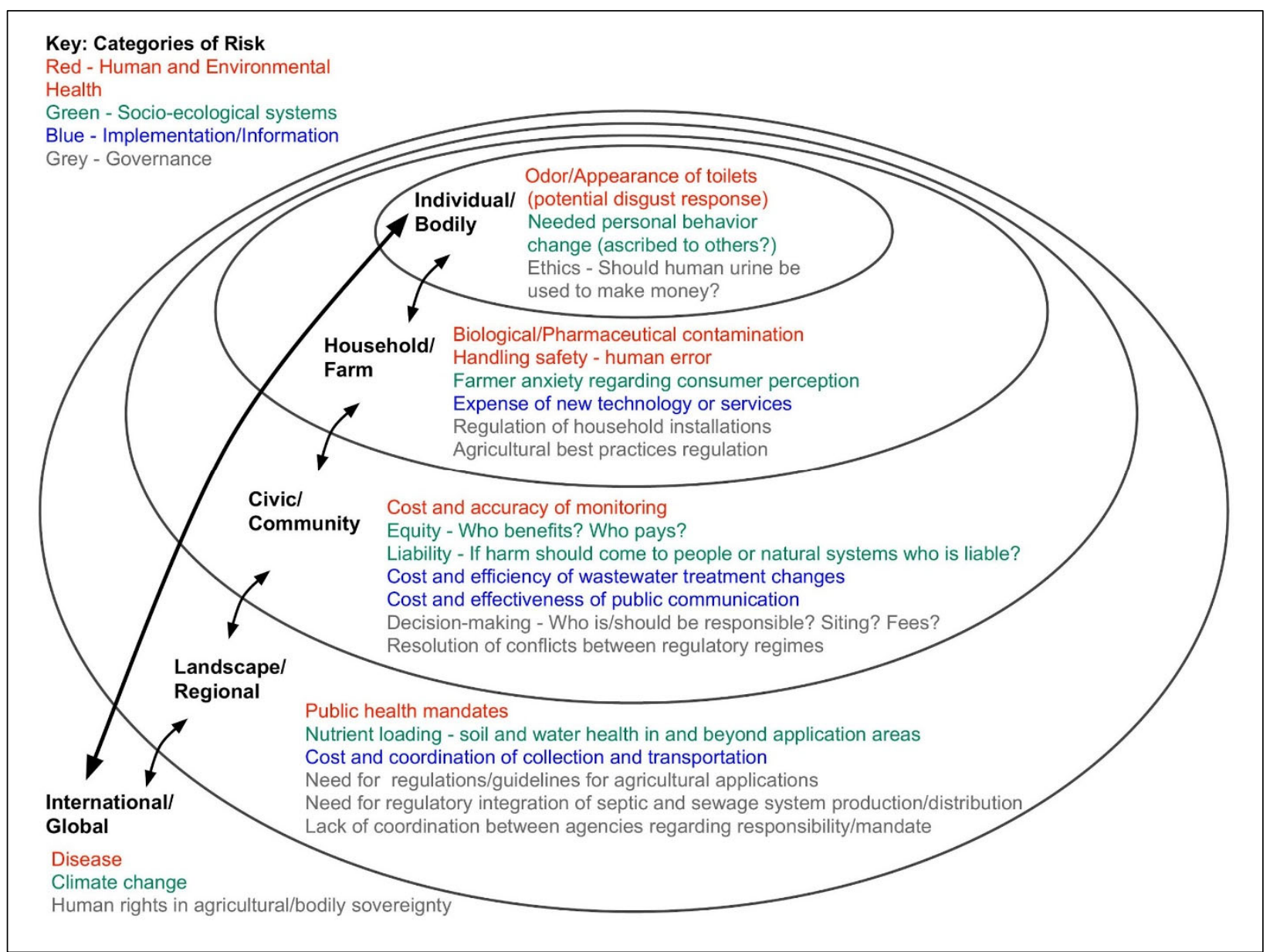

This comment suggests that questions of responsibility are closely related to concerns about which individuals and organizations can be trusted to make the most appropriate decisions and on what basis. Our coding on the question of trust of authorities was scaled from least trusting to most. However, even when reviewing comments coded as most trusting, many respondents expressed varying degrees of skepticism about whom they could trust, and when. For example, one respondent asked: "What is the rest of the world doing about this stuff? Because I might trust the government in
Norway more than the United States. ... So if the Norwegian government said this was great for our people then maybe that might be good to know!" (General Public Focus Group 2, 2017). There was anxiety about industry influence in both government and science and fear that potential risks are not being communicated accurately or are underreported.

Some respondents also raised ethical concerns about who might benefit from the use of their urine. As one focus group participant put it, 
Something I'm really not okay with is this system being used to make a profit for people to get really rich? That to me is just ethically wrong. And I didn't even think about it until now, but just thinking of it that way ... It just rubs me the wrong way. I think it's ethically wrong to make money off it because it's from humans. (General Public Focus Group 1, 2017)

Respondents emphasized that local decisionmakers such as town managers, planners, and farmers need to be involved as urine diversion is scaled up. Some also questioned the very notion of "scaling up" because of the potential loss of local agency in response to their questions about fairness and equity in the development of UDFs.

Farmers in our focus groups and interviews were clear that in order to use this product they would need to know its nutrient analysis, including micronutrients, and they would want data for yield results over several years. They would also want to know how soil health is affected over time. One farmer who is currently partnering with Rich Earth and applying urine on hay would want more data before using it on vegetables: "I haven't yet seen the information to understand what's passing through and building up.... I'd want to see, like, to be honest, 15 years of data that, like, pharmaceuticals and God knows what else we put into our bodies, isn't getting built up in the soil" (Vermont Farmer 2, 2017). Farmers also wanted to better understand when the nutrients in urine would be most available to plants, and to see guidelines for the most effective application to benefit crops and reduce nutrient losses. Some wanted testing to ensure the palatability of urine-fertilized pasture for their livestock, particularly for goats.

As with the general public group, farmers had substantial concern that research is unduly influenced by industry. One of the farmers currently partnering with Rich Earth Institute remarked:

I very definitely view [most research results] with ... a healthy skepticism.... The research they do is always funded by somebody and the people who have the money to do that are monied interests in business. ... I'm not inter- ested in big money of any kind making decisions for the rest of us. (Vermont Farmer 1, 2017)

This led to questions about how and by whom UDFs should be certified as safe for crops (both those used for human consumption and those for animal feed) and of consistent quality. Our farmer focus groups included several farmers who described themselves as "organic, not certified." Nonetheless, they hoped UDFs could be approved by the USDA National Organic Program (NOP) for use on organic farms. They suggested that potential impacts on soil health would need to be addressed and "there would have to be a certain amount of convincing those that approve or certify organic farms, and that would all be a part of that process, figuring out whether it had any detrimental effects on the soil function" (Farmer Focus Group 2, 2018).

Some farmers also offered suggestions to address these concerns. A few indicated they would want to make sure there was some sort of liability insurance to indicate that the product had been properly tested so that, in case someone got ill later, the farmer could not be held responsible. They also recommended working with supermarkets, co-ops who buy farmers' products, and the fertilizer industry to address any regulatory and labeling concerns that may arise and influence marketing strategies. Farmers expressed a desire to work in partnership with scientists and regulators to ensure that their own concerns for human, livestock, and environmental health were addressed.

Like the farmers, the specialists we interviewed wanted to see a comprehensive analysis of the components in UDF, including macro and micro nutrients and the specific chemical formulations of each. They wanted this analysis to include any potential microconstituents such as pharmaceuticals, heavy metals, or hormones, and to see how any levels found in UDF compared to those in water supplies, wastewater, and other existing environmental sources. They also thought yield trials (for a range of crops) would be helpful. They sought studies on microconstituents' uptake in plant tissue and impacts on soil microorganisms, as well as studies on the environmental fate of the nutrients 
in UDF and best practices to prevent leaching and volatilization.

Some specialists with experience in the operation or regulation of wastewater treatment systems pointed out the need for more information on how urine diversion's removal of nutrients from influent would affect biological treatment processes. They also thought it would be useful to have more data on the flow reduction caused by urine diversion and its resulting potential to extend the life of a given wastewater treatment system. For example, one Vermont legislator, thinking about economic concerns in her community, mused:

[What if] you could sort of sugar off the most motivated people in a town ... and say "You know what? We actually could postpone expensive infrastructure upgrades for $\mathrm{x}$ number of years if we had 500 people willing to do this." ... And I'm interested in, what does that do? Does it help the lake? Does it prolong the life of their treatment plant? Can it help make combined sewer overflows, which is a chronic problem in that town, less polluting, you know, and I hope that's gonna [be] where ... your next level [of research] is gonna take us. (Vermont Legislator 2, 2017)

Compared to farmers and the general public, the specialists we interviewed had more confidence in regulatory and government processes and want to be involved in these processes, but they were concerned that decision-making often is not backed by sufficient evidence. A soil scientist expressed skepticism about the possibility that science would necessarily be used appropriately, and go deeply enough:

Just looking at this as an organic nitrogen application, and therefore good ... I don't know what your team, the depth of your analysis about this, but I think it should be critically evaluated as far as what the effects are, into aquatic and terrestrial systems, of applying a very high nitrogen fertilizer source. Even if it is organic, and even if it is diverted from the waste stream.... On the surface it looks good, but when you dig deeper, it may not really be. (New Hampshire Soil Scientist, 2018)

Specialists also pointed out conflicting priorities and distrust between different groups and agencies, and acknowledged that each stakeholder group does not necessarily understand the needs of other groups. For example, a New England agricultural educator noted farmers' needs have not always been fully recognized when developing fertilizers from waste materials. She cited cases in Massachusetts where farms were overloaded with nutrients as developers worked to site digesters that process urban organic waste on farms:

[A] company will come to the farms saying, "We'll install the digester ... and then you get free fertilizer. No big deal." Regulations allow them to bring up to 70 , maybe $80 \%$ of offfarm waste into these digesters. And then these farms are overloaded. (Massachusetts Agricultural Educator, 2018)

Farmers are unable to move the digestate fertilizer they cannot use to other farms because of the high cost of transportation, and this agricultural educator imagined the same could be true of liquid urine.

Many of the specialists we interviewed emphasized that facilitating understanding across various spheres of influence on the topic is critical. For example, a legislator noted that when trying to promote a practice, if other decision-makers do not know about or understand the research behind it, "[the idea] is dead. I mean, it just isn't going to happen, and so the political class needs education and bringing along" (Vermont Legislator 2, 2017).

However, a New England planner pointed out that in terms of determining how best to manage human waste, now may be the opportune moment to have these conversations because "one of the challenges [regulatory agencies are] recognizing is that the cost of all the traditional approaches [is high] and isn't working [laughs]." As a result, the planner said, agencies are:

working on updating both the environmental protection rules, which are the rules for the 
[smaller scale] onsite wastewater... as well as the indirect discharge rules, which are the rules for the soil-based, larger community-scale systems ... and I think that's a good opportunity to begin some of these discussions about flow diversion and flow separation. (Vermont Planner, 2018)

\section{Discussion}

Language such as "begin some of these discussions" is a cue from an experienced planner that relationship-building is crucial to regulatory and practice outcomes, echoing what risk scientists since Short (1984) have asserted: "perceptions of risk, including judgments as to the acceptability of particular risks, are a function of the degree to which the institutions which are responsible for the assessment and management of risks are trusted" (p. 714). And, as Lachapelle (2008) points out, successful community development research and practice must build this trust if participants are to feel a sense of ownership in the development process. The important window of opportunity represented by our aging wastewater treatment systems in the face of climate extremes and demographic changes may pave the way for solutions like UDFs to emerge and take root, beginning with these conversations in local communities. However, the value of UDFs for reducing risks from reliance on imported agricultural inputs must be balanced with an awareness of the types of nested risks and responsibilities perceived by all those affected-in this case, all of us who consume food and produce waste.

It remains to be seen in practice whether the cost savings represented by urine diversion-both in terms of agricultural productivity and waste-water system safety and efficiency — can be achieved over time locally, and expand at scale geographically. For example, a nutrient management advisor pointed out that New Hampshire's regulations concerning the use of biosolids are different than Vermont's; the advisor imagined this may be the case with urine (New Hampshire Agricultural Advisor, 2019). However, common trends across sites exist as well, such as farmers' interests in environmental stewardship and in organic production (USDA, 2017). As economist Veronica Nigh writes in an American Farm Bureau Federation analysis of the USDA 2017 census:

Farmers increased the number of acres of cropland planted to a cover crop by nearly 50 percent. Further, the number of operations with renewable energy devices increased by 132 percent. This huge increase was driven by large increases in the number of operations with solar panels, wind turbines, methane digesters and geo-exchange systems. (Nigh, 2019)

This environmental orientation on the part of many farmers may indicate potential interest in the reuse of human urine in agriculture and suggests that certification of UDFs as organic at the federal level could both enable more farmers to use UDFs and help mitigate regional differences in regulation. While our data are not adequate to assess regional differences writ large, they do indicate that specialists and agricultural producers are mindful of the importance of regulations that can enable or constrain innovation.

Regarding the potential effect of system redesign on local communities, farmers in this study saw the value of recycling human urine as part of strengthening local economies. But at the same time, some worried that commodification of urine as a fertilizer could translate into the inequalities already embedded in agricultural systems. Farm inputs are increasingly provided by conglomerates beyond local or regional production communities, creating what Richard Lewontin (1998) described as "agricultural alienation." Pushing back against evolutionary psychology and sociobiology as explanations for inequality, Lewontin draws conscious parallels with labor alienation in industrial sectors, but notes that farmers face even deeper anxieties of having land, water, and food become commoditized and beyond the reach of an individual or family. In small farm communities that are struggling to retain a sense of sovereignty (or cultural and technological control—see Anderson et al., 2018) over their practices, individuals might fear the hidden exploitative possibilities of separating people from their waste in new ways.

This constitutes one of the wider layers in our 
nested risk concept (see Figure 1), speaking not only to the fear of being exposed to something bad, but also to the fear of losing access to that which is deemed good or natural in life (Colsa Perez et al., 2015). In general, with regard to informed, equitable participation in environmental decision-making, Webler, Tuler, and Kruger (2001) find that for the process to be seen as legitimate, "technical information as well as local knowledge [emphasis added] needs to be gathered ... evaluated in valid ways ... and used to support recommendations" (p. 441).

Many of our respondents are already mindful of and collecting evidence about nested risks, including hydrological variations that play into nutrient runoff, contamination events, and toxin exposure from a wide range of sources. They expressed a need for more data on the microconstituents of existing industrially manufactured agricultural inputs like imported fertilizers as well as the natural amendments currently used by many organic and ecologically oriented farmers.

This reflects the ways that financial risk is increasingly nested within notions of moral and physical risk, particularly when we consider our dominion over most of the planet and its consequences for our health over the long term and for the existence of other life forms. Future research on these topics might leverage such partnerships for civically engaged and citizen scientific work on ecology and soil microbiology. Such data collection and modeling of complex agricultural systems can and should combine with further agroecological and policy research to feed findings such as ours into systemic work toward safer, more resilient, and just agricultural systems. Our conceptualization of ways in which ongoing research can be co-created to reflect the priorities revealed by our respondents is illustrated in Figure 2.

The opportunities and challenges noted by our interviewees provide important guidance for research and experimentation going forward. For example, researchers with our larger INFEWS project are working on concentrating urine to reduce transportation costs and labor requirements and continue to work on appropriate treatment methods to reduce microcontaminants. Coupled human/natural systems research could be applied productively to understand and predict UDF implications for soil health under different soil type and management scenarios. Such a complex systems-based focus could also enable current UDF related research, such as that underway for specific crops, sites, and application protocols (see, for example, Pradhan et al., 2010), to be connected with research on environmental impacts within wider food and water systems (Tidåker et al., 2007). As advancing climate change affects growing seasons, hydrological conditions, and agricultural management regimes, this becomes especially important.

This work might best be conducted in relation to other sustainable agricultural inputs, like recycled water. Foundations from this part of the project can undergird ongoing dialogue and documentation of early adoption. Teams should continue to collect adaptation and implementation insights to shape the potential for scaling forward, both within and across ecologically distinct regions with different regulatory contexts.

Limitations of this study include the small numbers of focus groups, relatively small numbers of individuals interviewed, the narrow demographic range of respondents, and some aspects of the sites where the research was conducted. For example, in Vermont, Brattleboro is perceived by some from other areas as being the "granola belt" where green and progressive ideas are more prevalent than in other parts of the state. Similar differences exist between urban and rural farms in the state of Michigan, and across northern versus other parts of the state (recognizing that suburbs can have more and less rural or urban characteristics in ways that are historically linked to septic versus main sewer line infrastructures; see Rome, 2001). Ann Arbor, where the UM team is based, has a comparable role in the state of Michigan, and is often described teasingly as a "bubble" or "the people's republic of Ann Arbor." That said, one aspect of our team's mandate was to ascertain existing enthusiasms or concerns among relevant stakeholders and communities of potential adopters. This was intended to enable co-creation, with relevant organizations and individuals, of the educational tools that could support learning, adoption, and eventual regulation of alternatives to 


\section{Figure 2. Priorities for Research and Co-creation}

Figure 2 parallels our initial representation of the nested risks revealed by our research, to show priorities for action research going forward, reflective of those concerns. The color coding here represents categories for co-creation of research and implementation strategies and tools across permeable scales. Red suggests research in the realm of human and environmental health; green concerns wider socio-ecological systems; blue concerns methods of communication and implementation; and grey addresses governance, policy, and regulation.

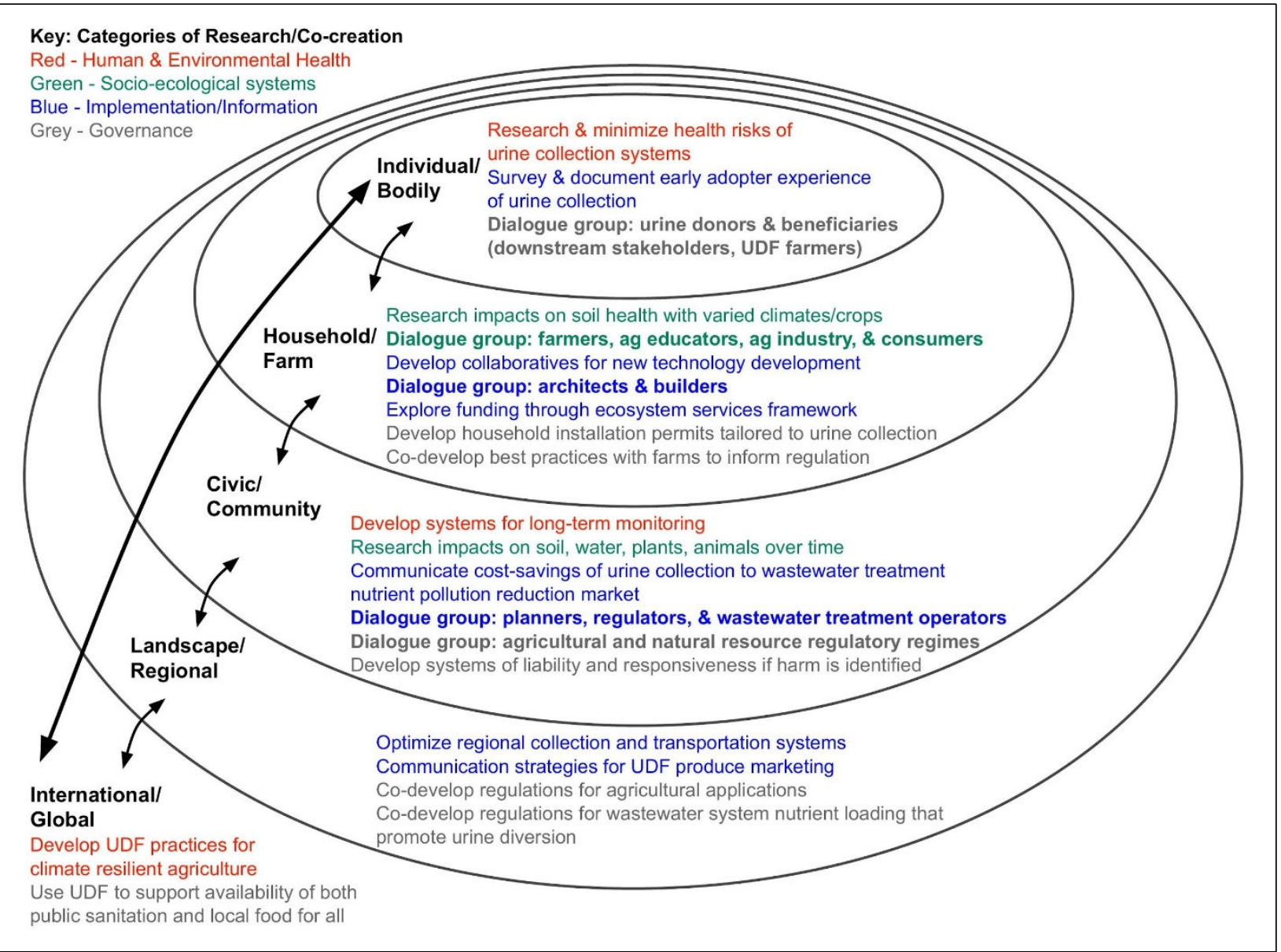

current commercial fertilizers in a range of social and geographic circumstances. We hence see this less as a limitation than as a condition of the research, one that is relevant for future work in distinct sites, and comparable across the two sites. We recognize, however, that the type of in-depth dialogue needed for inclusive processes leading to technological change requires long-term commitments and partnerships that the present research has only begun to generate. We advocate for multidisciplinary teams across academic, practitioner and grassroots organizations to utilize this initial work to foster a range of follow-up action research.

\section{Conclusion}

Our results point to the necessity that researchers recognize the nested risks that entail shared responsibility by co-creators of this innovation. If an appropriate dialogical process can be developed in response to these perceived risks and responsibilities, the implementation of such systemic change could be effectively assessed and adapted (see Webler et al., 2001) beyond the pilot communities of relatively small and varied farms like those around Brattleboro, Vermont, in New England, to include more large-scale, commodity-oriented agricultural economies like those in Michigan in the Upper Midwest. 
The data analyzed here (interviews, focus groups) can be mined for content and tone in future convenings of stakeholders. Given that the development and introduction of UDFs might entail modifications not only of farming practice, but also of personal hygiene practices at home and in public infrastructure, this work should continue to build robust dialogue and collaboration over time such that pilot and prototype communities can feel ownership of and trust in these co-created innovations.

To scale and assess such adaptive changes further will require consistent respect for those internalizing the varied levels of risk that come with changing practices. It will also require sharing knowledge between policy-makers, farmers, and consumers in order to "stay with the trouble" (Haraway, 2016). In other words, we must continue to heed the concerns and opportunities identified by our participants through dialogue mechanisms that engage a wide range of perspectives in a given place. Such "dialogue territorial" prioritizes the accessibility and transparency of new technologies and is anchored regionally in particular communities and places (Les Greniers de l'Abondance, 2020). Such foundations are crucial for cross-regional dialogue and leverage the cumulative experience of misapplied products, mismeasured impacts, and unintended consequences, recounted only in part here. Such experiences - failures as well as successes - are a kind of renewable resource themselves. They bear witness to the ways that sharing knowledge in families, farms, and communities has long constituted the foundation of human experimentation for positive transformation.

\section{Acknowledgments}

We thank Phoebe Gooding, Chris Askew, and Malavika Sahai, who helped conduct literature reviews and administer focus groups, surveys, and interviews. We also acknowledge Linda MacPherson of New Water Resources, who designed an animation with the Rich Earth Institute that we deployed in focus groups and survey research to explore educational impacts.

\section{References}

Abeysuriya, K., Fam, D., \& Mitchell, C. (2013). Trialling urine diversion in Australia: Technical and social learnings. Water Science and Technology: A Journal of the International Association on Water Pollution Research, 68(10), 2186-2194. https://doi.org/10.2166/wst.2013.473

Alaimo, S. (2016). Exposed: Environmental politics and pleasures in posthuman times. University of Minnesota Press. https://doi.org/10.5749/minnesota/9780816621958.001.0001

Anderson, C., Maughan, C., \& Pimbert, M. P. (2018). Transformative agroecology learning in Europe: Building consciousness, skills and collective capacity for food sovereignty. Agriculture and Human Values, 36, 531-547. https://doi.org/10.1007/s10460-018-9894-0

Aparicio, A. (Host). (2019, January 25). Something's in the water [Audio podcast episode]. In It's hot in here. http://www.hotinhere.us/podcast/somethings-in-the-water/

Beck, U. (1992). Risk society: Towards a new modernity (M. Ritter, Trans.). Sage Publishers. (Original work published 1986)

Blair, B., Lovecraft, A. L., \& Kofinas, G. P. (2014). Meeting institutional criteria for social resilience: A nested risk system model. Ecology and Society, 19(4), Article 36. https://doi.org/10.5751/ES-06944-190436

Carney, M. (2012). "Food security" and "food sovereignty": What frameworks are best suited for social equity in food systems? Journal of Agriculture, Food Systems, and Community Development, 2(2), 71-87. https://doi.org/10.5304/jafscd.2012.022.004

Cavicchi, J., Davis, E., Gaynor, C., Kennedy, B., Lally, C., Nace, K., \& Noe-Hays, A. (2020). Village Sanitation Pilot Study: Uniting land use planning, community development, and eco-sanitation in southeastern Vermont. Rich Earth Institute, Windham Regional Commission, \& Nutrient Networks. https://richearthinstitute.org/village-sanitation-pilot-study/

Colsa Perez, A., Grafton, B., Mohai, P., Hardin, R., Hintze, K., \& Orvis, S. (2015). Evolution of the environmental justice movement: Activism, formalization and differentiation. Environmental Research Letters, 10(10), Article 105002. https://doi.org/10.1088/1748-9326/10/10/105002 
Cook, S., Sharma, A., Pamminger, F., Narangala, R., \& Fernando, R. (2013). Kinglake West Sewerage Project: Postimplementation project review. CSIRO \& Yarra Valley Water. https://www.yumpu.com/en/document/read/34102382/kinglake-west-sewerage-project-yarra-valley-water

Haraway, D. J. (2016). Staying with the trouble: Making kin in the Chthulucene. Duke University Press. https://doi.org/10.1215/9780822373780

Heiss, S. N., \& Suozzo, A. (2020). Going rogue for raw milk: Experience and values as consumer filters for conflicting raw milk discourses. Journal of Agriculture, Food Systems, and Community Development, 9(3), 301-315. https://doi.org/10.5304/jafscd.2020.093.034

Hilton, S. P., Keoleian, G. A., Daigger, G. T., Zhou, B., \& Love, N. G. (2021). Life cycle assessment of urine diversion and conversion to fertilizer products at the city scale. Environmental Science \& Technology, 55(1), 593-603. https://doi.org/10.1021/acs.est.0c04195

Ishii, S. K. L., \& Boyer, T. H. (2016). Student support and perceptions of urine source separation in a university community. Water Research, 100(1), 146-156. https://doi.org/10.1016/j.watres.2016.05.004

Jones, C. C. (2011). Environmental justice in rural context: Land-application of biosolids in central Virginia. Environmental Justice, 4(1), 1-15. https://doi.org/10.1089/env.2009.0034

Knoch, C. (2018, February 24). Qualitative data analysis using Microsoft Word comment. Carsten Knoch. https://carstenknoch.com/2018/02/qualitative-data-analysis-using-microsoft-word-comments/

Lachapelle, P. (2008). A sense of ownership in community development: Understanding the potential for participation in community planning efforts. Community Development, 39(2), 52-59. https://doi.org/10.1080/15575330809489730

Legrand, M., Jovéniaux, A., Arbarotti, A., de Gouvello, B., Esculier, F., \& Tabuchi, J.-P. (2020, December 1-4). The emergence of systems for the source separation and valorization of human waste in Greater Paris: From necessity to implementation [Paper presentation]. Second International Conference for Water, Megacities and Global Change, Paris. https://www.leesu.fr/ocapi/wp-content/uploads/2020/12/Legrand-al EauMega-2020 VF.pdf

Les Greniers de l'Abondance. (2020). Voies de résilience: No. 11 - Recycler massivement les nutriments [Roads to Resilience: \#11-Massively recycling nutrients]. In Vers la resilience alimentaire: Faire face aux menaces globales a l'echelle territoriale [Towards food resilience: Addressing systemic threats at the territorial level] (pp. 150-176). https://resiliencealimentaire.org/

Lewontin, R. C. (1998). The maturing of capitalist agriculture: Farmer as proletarian. Monthly Review, 50(3), $72-84$. https://doi.org/10.14452/MR-050-03-1998-07_6

Lienert, J., Haller, M., Berner, A., Stauffacher, M., \& Larsen, T. A. (2003). How farmers in Switzerland perceive fertilizer from recycled anthropogenic nutrients (urine). Water, Science, \& Technology, 48(1), 47-56. https://doi.org/10.2166/wst.2003.0013

Lienert, J., Thiemann, K., Kaufmann-Hayoz, R., \& Larsen, T. A. (2006). Young users accept NoMix toilets — a questionnaire survey on urine source separating toilets in a college in Switzerland. Water Science \& Technology, 54(1112), 403-412. https://doi.org/10.2166/wst.2006.920

MacPherson, L. (2015). Public outreach for informed acceptance. World Water: Water Reuse \& Desalination, 6(2), 14. http://newwaterresources.com/wp-content/uploads/2015/09/world water-waterReuseAndDesalinationsummer2015.pdf

Mason-Renton, S. A., \& Luginaah, I. (2018). Conceptualizing waste as a resource: Urban biosolids processing in the rural landscape. The Canadian Geographer / Le Géographe canadien, 62(2), 266-281. https://doi.org/10.1111/cag.12454

Nigh, V. (2019). The 2017 census of agriculture, our first take. American Farm Bureau Federation. https://www.fb.org/market-intel/the-2017-census-of-agriculture-our-first-take

Ormerod, K. J. (2016). Illuminating elimination: Public perception and the production of potable water reuse. WIREs Water, 3(4), 537-547. https://doi.org/10.1002/wat2.1149

Pahl-Wostl, C., Schönborn, A., Willi, N., Muncke, J., \& Larsen, T. A. (2003). Investigating consumer attitudes towards the new technology of urine separation. Water Science \& Technology, 48(1), 57-65. https://doi.org/10.2166/wst.2003.0015 
Pradhan, S. K., Holopainen, J. K, Weisell, J., \& Heinonen-Tanski, H. (2010). Human urine and wood ash as plant nutrients for red beet (Beta vulgaris) cultivation: Impacts on yield quality. Journal of Agricultural and Food Chemistry, 58(3), 2034-2039. https://doi.org/10.1021/if9029157

Rome, A. (2001). The bulldozer in the countryside: Suburban sprawl and the rise of American environmentalism. Cambridge University Press. https://doi.org/10.1017/CBO9780511816703.005

Saldaña, J. (2015). The coding manual for qualitative researches (3rd ed.). Sage. https://uk.sagepub.com/en-gb/eur/the-coding-manual-for-qualitative-researchers/book243616

Sayre, N. F. (2009). Scale. In N. Castree, D. Demeritt, D. Liverman, \& B. Rhoads (Eds.), A companion to environmental geography (pp. 95-108). Blackwell. https://doi.org/10.1002/9781444305722

Schreiber, T., Opperman, S., Nace, K., Pallmeyer, A. N., Love, N., \& Hardin, R. (2020). Leveraging integrative research for inclusive innovation: Urine diversion and re-use in agriculture. Elementa: Science of the Anthropocene, 8, Article 12. https://doi.org/10.1525/elementa.408

Segrè Cohen, A., Love, N. G., Nace, K. K., \& Árvai, J. (2020). Consumers’ acceptance of agricultural fertilizers derived from diverted and recycled human urine. Environmental Science \& Technology, 54(8), 5297-5305. https://doi.org/10.1021/acs.est.0c00576

Short, Jr., J. F. (1984). The social fabric at risk: Toward the social transformation of risk analysis. American Sociological Review, 49(6), 711-725. https://www.jstor.org/stable/2095526

Simha, P., \& Ganesapillai, M. (2017). Ecological Sanitation and nutrient recovery from human urine: How far have we come? A review. Sustainable Environment Research, 27(3), 107-116. https://doi.org/10.1016/j.serj.2016.12.001

Stern, M. J., \& Baird, T. D. (2015). Trust ecology and the resilience of natural resource management institutions. Ecology and Society, 20(2), Article 14. https://doi.org/10.5751/ES-07248-200214

Tidåker, P., Mattsson, B., \& Jönsson, H. (2007). Environmental impact of wheat production using human urine and mineral fertilisers - a scenario study. Journal of Cleaner Production, 15(1), 52-62. https://doi.org/10.1016/i.jclepro.2005.04.019

Tornaghi, C. (2017). Urban agriculture in the food-disabling city: (Re)defining urban food justice, reimagining a politics of empowerment. Antipode, 49(3), 781-801. https://doi.org/10.1111/anti.12291

U.S. Department of Agriculture, National Agricultural Statistics Service [USDA NASS]. (2017). USDA agricultural census 2017 census volume 1, chapter 1: U.S. national level data. Retrieved August 12, 2019 from https://www.nass.usda.gov/Publications/AgCensus/2017/Full_Report/Volume_1,_Chapter_1_US/

Vinnerås, B., Palmquist, H., Balmér, P., \& Jönsson, H. (2006) The characteristics of household wastewater and biodegradable solid waste-A proposal for new Swedish design values. Urban Water Journal, 3(1), 3-11. https://doi.org/10.1080/15730620600578629

Webler, T., Tuler, S., \& Kruger, R. (2001) What is a good public participation process? Five perspectives from the public. Environmental Management, 27, 435-450. https://doi.org/10.1007/s002670010160

Wilde, B. C., Lieberherr, E., Okem, A. E., \& Six, J. (2019). Nitrified human urine as a sustainable and socially acceptable fertilizer: An analysis of consumer acceptance in Msunduzi, South Africa. Sustainability, 11(9), Article 2456. https://doi.org/10.3390/su11092456 


\section{Appendix A. Focus Groups and Interviews}

Focus Groups (these represent a subset of the 5 focus groups conducted)

Farmer Focus Group 1, Facilitator: Tatiana Schreiber, with Phoebe Gooding. Brattleboro, Vermont. 15 March 2018.

Farmer Focus Group 2, Facilitator: Tatiana Schreiber, with Phoebe Gooding. Brattleboro, Vermont. 21 March 2018.

General Public Focus Group 1, Facilitator: Audrey Pallmeyer, with Chris Askew-Merwin. Ann Arbor, Michigan. 14 August 2017.

General Public Focus Group 2, Facilitator: Tatiana Schreiber, with Phoebe Gooding. Brattleboro, Vermont. 10 August 2017.

Interviews (these represent a subset of the 24 interviews conducted)

Massachusetts Agricultural Educator, Interview with Tatiana Schreiber, with Alex Sabido. Amherst, Massachusetts. 6 June 2018.

Massachusetts Environmental Advocate, Interview with Tatiana Schreiber. Greenfield, Massachusetts. 3 August 2017.

New Hampshire Agricultural Advisor, Interview with Tatiana Schreiber. Walpole, New Hampshire. 4 April 2019.

New Hampshire Soil Scientist, Interview with Tatiana Schreiber. Keene, New Hampshire. 26 June 2018.

Vermont Agricultural Educator, Interview with Tatiana Schreiber, with Malavika Sahai and Audrey Pallmeyer.

Burlington, Vermont. 1 March 2017.

Vermont Farmer and Environmental Advocate, Interview with Tatiana Schreiber, with Phoebe Gooding. Woodstock, Vermont. 18 June 2018.

Vermont Farmer 1, Interview with Tatiana Schreiber, with Audrey Pallmeyer and Malavika Sahai. Brattleboro, Vermont. 28 February 2017.

Vermont Farmer 2, Interview with Tatiana Schreiber, with Audrey Pallmeyer and Malavika Sahai. Brattleboro, Vermont. 28 February 2017.

Vermont Legislator 1, Interview with Tatiana Schreiber, with Phoebe Gooding. Westminster West, Vermont. 2 August 2017.

Vermont Legislator 2, Interview with Malavika Sahai, with Tatiana Schreiber and Audrey Pallmeyer. Montpelier, Vermont. 1 March 2017.

Vermont Planner, Interview with Tatiana Schreiber, with Alex Sabido. Morristown, Vermont. 27 June 2018. 


\section{Appendix B. Coding Categories}

Bin 1.1: Familiarity (with concept of urine as fertilizer)

a) Yes, familiar-record stories

b) No, was not familiar

c) Formal training

Bin 1.2: Comfort Level (note what factors influence comfort level)

Scale: Low to high comfort level (e.g., would eat specific foods, would use on specific crops)

a) Low: Would not eat (or serve to family/friends)

b) Middle: Would use/eat $x$ crop, not y crop

c) High: Would eat/use on anything

Bin 2: Personal Response-e.g., disgust, discomfort, enthusiasm

Scale: Positive and negative feelings

a) Low: Disgust

b) Middle: Measured acceptance

c) High: Openness across the board

Bin 3: Ascribed Attitudes (feelings they think others will have)

Scale: Positive and Negative attitudes

a) Low: Think others will be opposed

b) Middle: Think others will be open in some cases

c) High: Enthusiasm

Bin: 4: Perceived Benefits: Environmental (Coder should note level of importance)

a) Water conservation

b) Soil health

c) Climate change

d) Less nutrient run-off into waterways

e) Other

Bin 5: Perceived Systemic Benefits OR Concerns: Economic or Infrastructural

a) Cost/efficiency of food

b) Cost/efficiency of wastewater treatment

c) Cost/consequences of fertilizer

d) Cost/efficiency of infrastructure changes (also how much people would spend on toilets)

Bin 6: Other Perceived Benefits of urine/diversion recycling including health

a) Help farmers, nutrients, value as fertilizer

b) Reduce chemical inputs

c) Urine or UDF may be less contaminated (risk to human) than current commercial fertilizers

d) Urine or UDF may be less contaminating (risk to environment) than current commercial fertilizers 
Bin 7: Holism-Concerns about natural cycles and human impact

Example: I don't like hydroponics because "they're growing in styrofoam or something, and rocks..."

a) Low: Transform nature to suit human needs

b) Moderate: Use some parts of nature for our needs, protect others

c) Strong: Reconnect natural cycles and close loops

\section{Bin 8: Humor}

a) Positive humorous response

b) Negative humorous response

Bin: 9: Perceived Community Concerns about Urine Diversion/Re-use

a) Perception of health risk (note type of health risk, e.g., opioids, other pharma, heavy metal, antibiotics, radiation, disease, fecal contamination)

b) Perception of risk to environment (note type of risk, e.g., water, soil)

c) Odor

d) Impact of treatment on fertilizer value (i.e., would treatment of UDF reduce fertilizer value-kill beneficial organisms, etc.)

e) Concern re what new toilets will be like/how they will work

\section{Bin 10: Attitudes Toward Authority And Science}

a) Being taken advantage of or talked down to

b) Being misled (by scientists, government agencies, corporations)

c) Human error causing health risk

d) Trust science and regulators to guide best practice

e) Other

Bin 11: Communication (suggestions, ideas)

a) Medium (animation, interviews with scientists)

b) Content (i.e., what they feel content should be)

c) Audience (which strategy for which audience)

d) Terminology/Language

e) Tone

f) Other

Bin 12: Uri (specific comments on Uri animation)
a) Medium (animation vs. other approach)
b) Content
c) Narration
d) Terminology/language
e) Tone
f) Other 


\section{Bin 13: Implementation}

a) Suggestions/comments about infrastructure

b) Suggestions/comments about implementation strategies

c) How much they would personally spend to change toilet, for example

d) Ideas about regulation (who in community should regulate; what types of regulation are needed, labeling or certifying?)

e) Implementation depends on scale

f) Implementation depends on geographic location

\section{Bin 14: Information Needs}

a) Data, research results

b) Technical specifics (how to apply, what happens to urine in storage)

c) Safety measures (i.e., what treatments were done, what were results)

d) Regulations (what regulations or guidelines are in place, questions about who will certify safety (including impact on soil health))

e) Economic information such as costs of implementation

f) Other

\section{Bin 15: Fertilizer Use Comments/Preferences}

a) Prefer untreated urine (i.e., for home/garden use)

b) Prefer treated, processed

c) Comments about biosolids in relation to urine or UDFs

d) Dry (concentrated) versus liquid

e) Preferred use depends on scale and type of operation

f) Other

\section{Bin 16: Decision-making about Food}

a) Economic

b) Environmental (thinks about environmental impact of how food is grown)

c) Health, nutritional value

d) Local, seasonal

e) Methods of growing (organic, conventional-thinks about fertilizer practices)

f) Perceived health risk (GMOs, pesticides)

g) Other 